\title{
Effect of different deformation and annealing procedures on non-magnetic textured Cu60Ni40 alloy substrates
}

Cui, Jin; Suo, Hong-li; Wang, Jin-hua; Grivel, Jean-Claude; Ma, Lin; Li, Chun-yan; Ji, Yao-tang; Kausar, Shaheen; Liu, Min; Wang, Yi

Published in:

International Journal of Minerals, Metallurgy and Materials

Link to article, DOI:

$10.1007 / \mathrm{s} 12613-018-1642-3$

Publication date:

2018

Document Version

Peer reviewed version

Link back to DTU Orbit

Citation $(A P A)$ :

Cui, J., Suo, H., Wang, J., Grivel, J-C., Ma, L., Li, C., Ji, Y., Kausar, S., Liu, M., \& Wang, Y. (2018). Effect of different deformation and annealing procedures on non-magnetic textured $\mathrm{Cu} N \mathrm{Ni}$ alloy substrates.

International Journal of Minerals, Metallurgy and Materials, 25(8), 930-936. htlfS:://d8i.org/10.1007/s12613-018$1642-3$

\section{General rights}

Copyright and moral rights for the publications made accessible in the public portal are retained by the authors and/or other copyright owners and it is a condition of accessing publications that users recognise and abide by the legal requirements associated with these rights.

- Users may download and print one copy of any publication from the public portal for the purpose of private study or research.

- You may not further distribute the material or use it for any profit-making activity or commercial gain

- You may freely distribute the URL identifying the publication in the public portal 


\title{
Effect of different deformation and annealing procedures on non-magnetic textured $\mathrm{Cu}_{60} \mathrm{Ni}_{40}$ alloy substrates.
}

\author{
Jin Cui1 ${ }^{1,2}$, Hongli Suo*1, Jinhua Wang ${ }^{1}$, Jean-Claude Grivel ${ }^{2}$, Lin $\mathrm{Ma}^{1}$, Chunyan $\mathrm{Li}^{1}$, Yaotang $\mathrm{Ji}^{1}$ \\ (1. Key Laboratory of Advanced Functional Materials, Ministry of Education, College of Materials Science and Engineering, Beijing University \\ of Technology, Beijing, 100124, China \\ 2. Department of Energy Conversion and Storage, Technical University of Denmark, Frederiksborgvej 399, 4000 Roskilde, Denmark)
}

\begin{abstract}
In this work, a series of specimens was prepared by the casting method. Sharp cube textured substrates were processed by heavy cold rolling and recrystallization annealing (RABiTS method). Both the rolling and the recrystallization texture in alloy tapes were investigated by means of X-ray diffraction and EBSD, respectively. The results showed that a strong copper-type deformation texture was obtained in the heavy cold rolled substrate. It also turns out that the recrystallization annealing process is very important to the texture transition in $\mathrm{Cu}-\mathrm{Ni}$ alloy substrates. The cube texture content in $\mathrm{Cu}_{60} \mathrm{Ni}_{40}$ alloy substrates reached $99.7 \%\left(\leq 10^{\circ}\right)$ by optimizing the cold rolling procedure and the recrystallizing heat treatment process, while the content of low-angle grain boundaries (from 2 to $10^{\circ}$ ) in the substrate reached $95.1 \%$.
\end{abstract}

Key words: Non-magnetic, CuNi alloy substrates; Annealing; Cube texture; Grain boundaries

\section{Introduction}

The second generation of high temperature superconducting tapes based on the $\mathrm{Y}_{1} \mathrm{Ba}_{2} \mathrm{Cu}_{3} \mathrm{O}_{7-\sigma}(\mathrm{YBCO})$ compound, has a large potential for many application, e.g. electricity, transport, high magnetic field devices, military and other applications [1]. Using rolling assisted biaxially textured substrates (RABiTS) [2] is one of the primary methods for the manufacture of coated conductors. As such metallic substrates, $\mathrm{Ni}-\mathrm{W}$ alloys have been widely studied and especially processing of $\mathrm{Ni}-5 \% \mathrm{~W}$ tapes $[3,4]$ has now reached a mature level for commercialization [5]. However, the Curie temperature of this alloy is $330 \mathrm{~K}$, and is ferromagnetic at $77 \mathrm{~K}$, which can produce magnetic hysteresis losses [6]. Some researchers studied the magnetic and mechanical property of non/low-level magnetic alloys, e.g. Ni-Cu binary alloys [6-11] and ternary Ni-base alloys [12-14], to find appropriate solutions. The price of $\mathrm{Cu}$ is $1 / 6$ of that of Ni and these two metals form a continuous solid solution. It was found that with a $\mathrm{Cu}$ content above $54 \%, \mathrm{Ni}-\mathrm{Cu}$ tapes are non-magnetic [12]. A. Tuissi et al. [15] studied the recrystallization texture as well as mechanical and magnetic properties of $\mathrm{Cu}-\mathrm{Ni}$ tapes, with 10 and $30 \% \mathrm{Ni}$, respectively. A. Girard et al. [7] studied $\mathrm{Cu}_{55} \mathrm{Ni}_{45}$ and $\mathrm{Cu}_{70} \mathrm{Ni}_{30}$ and the annealing procedures affecting grain boundary depth. It was observed that after annealing, both two alloys generate a partly twinned, strong cube texture. H.Q. Qiu et al. [16] produced $\mathrm{Cu}_{60} \mathrm{Ni}_{40}$ tapes by utilizing two annealing procedures, with a final cube texture content of $87.9 \%$. Vannozzi et al. [13] manufactured $\mathrm{Ni}-\mathrm{Cu}-\mathrm{Co}$ ternary alloy tapes where the cube texture content after annealing was $95 \%$. F. Fan et al. [17] found that in $\mathrm{Cu}_{60} \mathrm{Ni}_{40}$ tapes a sharp (001) texture could be obtained after annealing $1 \mathrm{~h}$ at $650-1000^{\circ} \mathrm{C}$.

However, there are only a few reports systematically analyzing sub-orientation and grain characterization of $\mathrm{Cu}-\mathrm{Ni}$ alloy tapes. This paper reports on non-magnetic $\mathrm{Cu}_{60} \mathrm{Ni}_{40}$ tapes produced by the RABiTS method, and studies both recrystallization texture and grain sub-orientation affected by cold rolling and annealing procedures in many details. Several microscopic techniques are applied to observe the differences between cold rolling and annealing.

\section{Experimental}

$\mathrm{A} \mathrm{Cu}_{60} \mathrm{Ni}_{40}$ ingot was prepared by vacuum induction melting of $99.9 \%$ pure metals. The ingot was hot forged into a rectangular shape with dimensions $20 \times 15 \times 10 \mathrm{~mm}^{3}$. After removing the oxide surface, the material was cold rolled, applying less than $5 \%$ reduction per pass until the final tape thickness (more than $95 \%$ total reduction). The samples were annealed in a protective atmosphere of $4 \% \mathrm{H}_{2}$ in Ar, following one-step or two-step annealing procedures.

The texture of the cold rolled substrates was investigated with a Bruker D8 X-ray goniometer. The microstructure, e.g. grain orientation distribution and grain boundary features of the recrystallized substrates was investigated with a SEM equipped with an Electron Back Scattering Diffraction setup (EBSD, JEOL JSM6500F), covering a region of $600 \mu \mathrm{m} \times 400 \mu \mathrm{m}$, with $4 \mu \mathrm{m}$ steps and an operating distance of $20 \mathrm{~mm}$, while the grain sizes were defined by $2^{\circ}$ misorientation.

\section{Results and discussion}

3.1 $\mathrm{Cu}_{60} \mathrm{Ni}_{40}$ tape deformation texture affected by the rolling procedure 

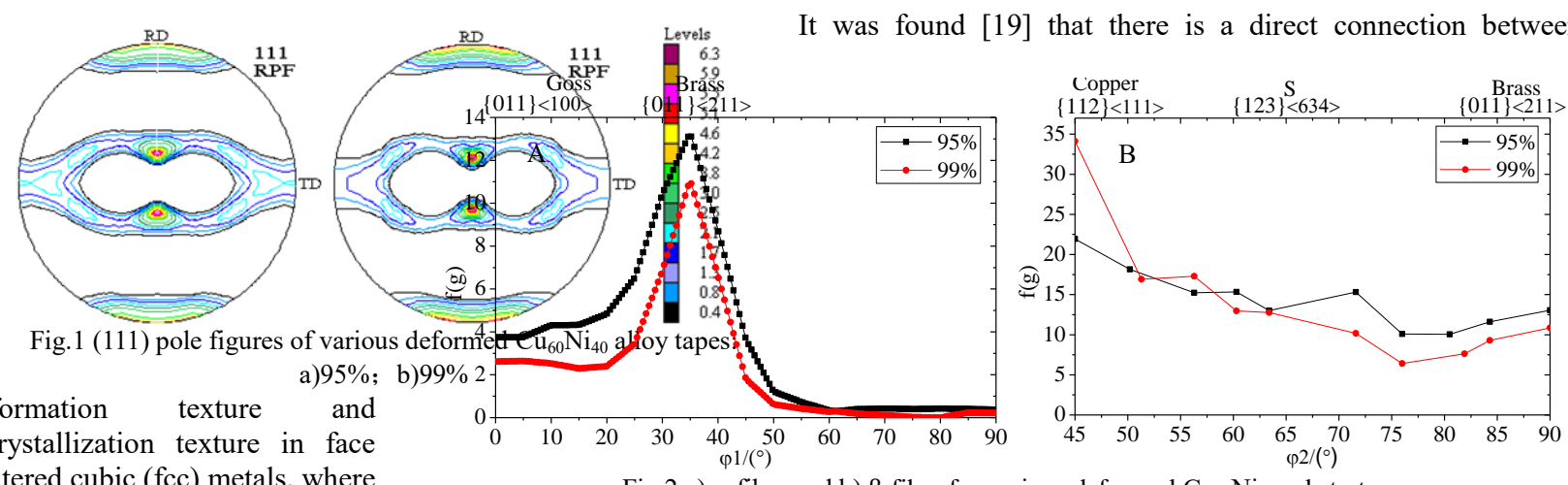
centered cubic (fcc) metals, where a strong Cube texture is obtained

Fig.2 a) $\alpha$-fiber and b) $\beta$-fiber for various deformed $\mathrm{Cu}_{60} \mathrm{Ni}_{40}$ substrates after annealing a Copper-type rolling texture, whereas mixed recrystallization is obtained after annealing of a mixed rolling texture, while a Cube texture couldn't be obtained after annealing Brass-type rolling texture. It is apparent that Copper and $\mathrm{S}$ orientations affect the generation of cube recrystallization while the rolling procedure affects the deformation texture. A Copper-type deformation texture can be obtained from high stacking fault energy fcc metals after strong deformation [18]. Fig. 1 shows (111) pole figures of highly deformed $\mathrm{Cu}_{60} \mathrm{Ni}_{40}$ alloy tapes (a. 95\%, b. 99\%). It can be seen that the two deformed alloys have typical Copper-

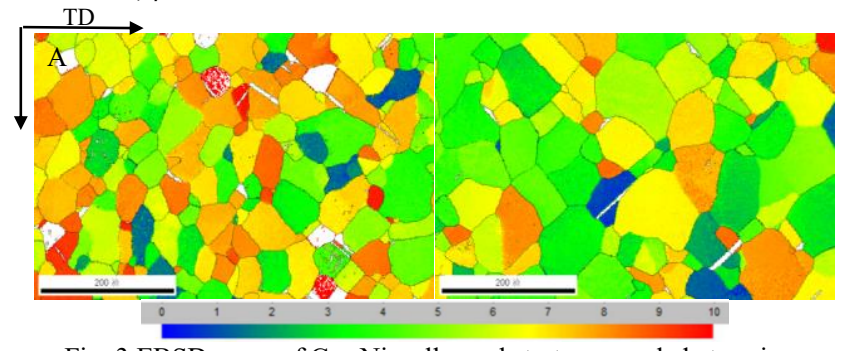

Fig. 3 EBSD maps of $\mathrm{Cu}_{60} \mathrm{Ni}_{40}$ alloy substrates annealed at various temperatures for $30 \mathrm{~min}$ : a) $1000^{\circ} \mathrm{C}$; b) $1050^{\circ} \mathrm{C}$ type rolling textures, and that with increasing deformation $\mathrm{S}^{\mathrm{RD}}$ and Copper orientations became more concentrated around their ideal orientation. For the effect of the degree of deformation on characterizing the rollingtexture, we studied the deformed $\mathrm{Cu}_{60} \mathrm{Ni}_{40}$ tapes $\alpha$-fiber and $\beta$-fiber (see Fig. 2). It can be seen that with increasing deformation, the amount of Goss and Brass orientation decreased slightly, whereas the Copper and S orientations became more concentrated around their phows show $99 \%$ deformation leads to a stronger Copper-type rolling texture, agreeing with Fig.1, and a stronger Cube recrystallization can be expected.

\subsection{The effect of the annealing procedure on $\mathrm{Cu}_{60} \mathrm{Ni}_{40}$ recrystallization texture}

After one-step annealing, the $99 \%$ deformed tape (5\% deformation per pass) was investigated by the means of EBSD technique for sub-orientation in different recrystallized samples. Figure 3 shows the EBSD maps of $\mathrm{Cu}_{60} \mathrm{Ni}_{40}$ substrates after annealing during 30 min at $1000{ }^{\circ} \mathrm{C}$ (sample A) or $1050{ }^{\circ} \mathrm{C}$ (sample B). The Cube orientation contents while the amount of low-angle grain boundary (2$10^{\circ}$ ) is, respectively, $96.1 \%, 98 \%, 75 \%$, and $86 \%$. After annealing, twins were generated in both samples. These alloys have high Cube contents, however, their proportions of low-angle grain boundaries are slightly low. The reason is that after annealing, the Cube

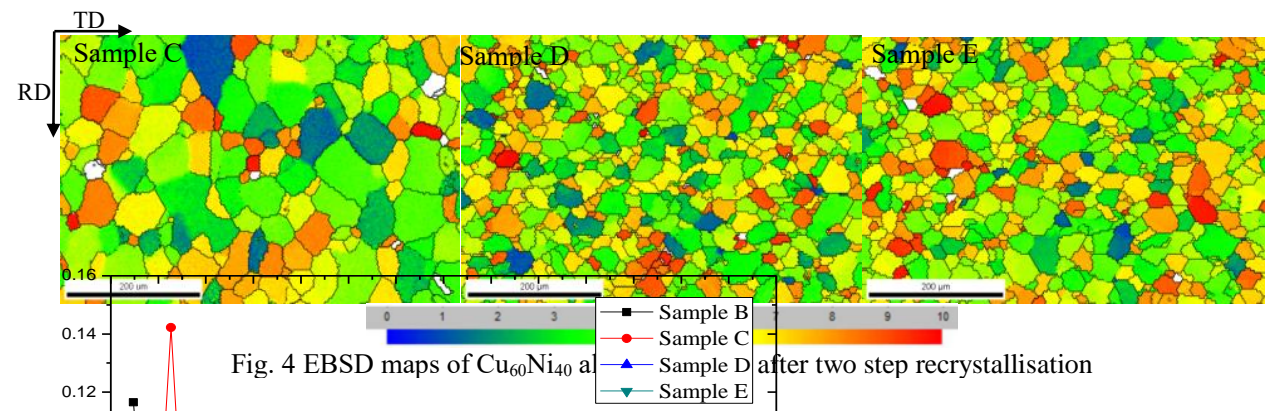
orientation $\left(\leq 10^{\circ}\right)$ deviated from the ideal cube texture, thus resulting in a misorientation between two adjacent cube oriented grains, and in the generation of some twins (see Fig. 3). It was reported $[19,20]$ that annealing twins and largeangle grain boundaries strongly affect the superconducting critical

Taple Two-step annealing processes with various parameters $.0 .10-$.

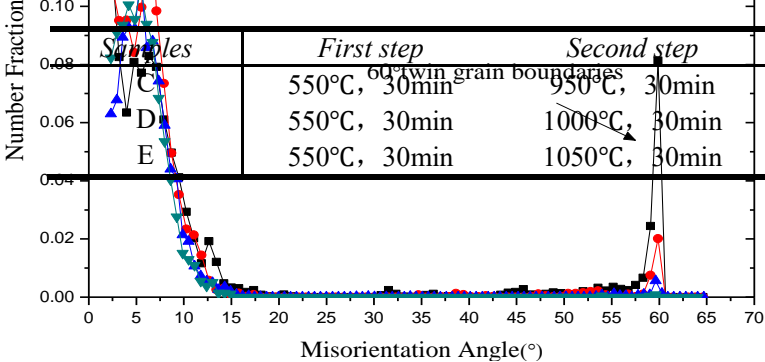

Fig. 5 Misorientation distributions in $\mathrm{Cu}_{60} \mathrm{Ni}_{40}$ tapes after various annealing processes current density $\left(\mathrm{J}_{\mathrm{c}}\right)$. In order to obtain a higher $\mathrm{J}_{\mathrm{c}}$, the non-cube oriented grains and annealing twins must be avoided, thus increasing the content of low-angle grain boundaries and Cube orientation. The content of twin boundaries decreased because of the increasing of annealing temperature (see Fig. 3 which shows sample B has the lower twin boundaries than sample A). However, there are several huge grains in sample B, in agreement with Ref. 21, which states that increasing temperature or longer annealing time will lead to abnormal grain growth and secondary recrystallization, at the expense of the generation of Cube oriented grains.

For eliminating annealing twin orientations and improving the quality of $\mathrm{Cu}_{60} \mathrm{Ni}_{40}$ alloy tapes, we annealed them by a two-step 
method. V. Subramanya Sarma [21] stated that two-step anneals can yield a higher Cube orientation content and better grain boundaries than one-step anneals in Ni-W/Ni-Cr complex alloy substrates. The two-step annealing procedure means that the alloy tapes are first annealed at a relatively low temperature for a given time, followed by annealing at a higher temperature anneal. The first annealing step contributes to the nucleation of Cube oriented grains . During the $2^{\text {nd }}$ step, the Cube oriented grains grow at the expense of the adjacent non-cube oriented grains, thus producing a higher content of cube recrystallization and lower deviation $\left(\leq 10^{\circ}\right)$ from the ideal cube texture in the substrate. The parameters of the first annealing step are very important for the final result. After $50 \%$ of the recrystallization process, according to Gerber et al. [22], the cube oriented grains have apparently the advantage among all

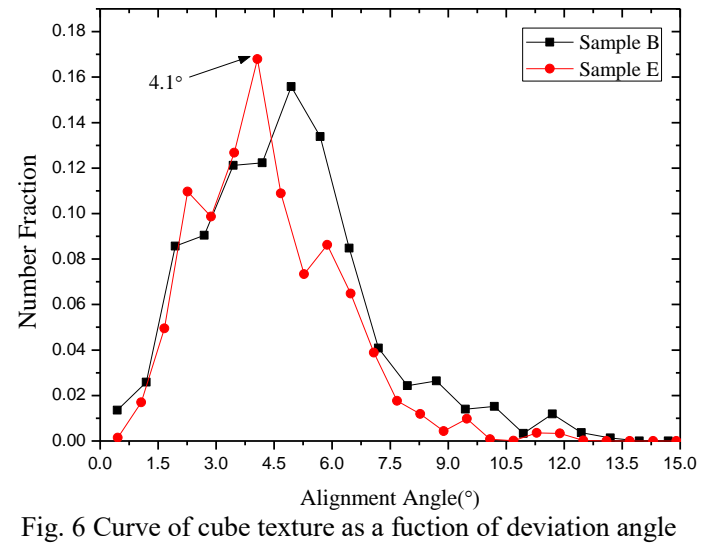

Fig. 6 Curve of cube texture as a fuction of deviation angle recrystallization grains. Since H.Q. Qiu [16] stated that recrystallization of $\mathrm{Cu}_{60} \mathrm{Ni}_{40}$ alloy tape reaches $50 \%$ after annealing for $30 \mathrm{~min}$ at $550{ }^{\circ} \mathrm{C}$, we used these parameters for the first annealing step.

Table 1 shows three kinds of two-step annealing parameters. In these processes, the first step was always $550{ }^{\circ} \mathrm{C} / 30 \mathrm{~min}$., while the second annealing step was performed at $950{ }^{\circ} \mathrm{C} / 30 \mathrm{~min}$ (sample C), $1000^{\circ} \mathrm{C} /$ $30 \mathrm{~min}$ (Sample D), or $1050^{\circ} \mathrm{C} / 30 \mathrm{~min}$ (sample E).

Figure 4 shows the sub-orientation maps of $\mathrm{Cu}_{60} \mathrm{Ni}_{40}$ alloy tapes after these different annealing procedures. The amount of cube orientation recrystallization texture was $98.7 \%, 99.4 \%$, and $99.7 \%$, respectively, i.e. the same level as commercial Ni-W alloy substrates. In particular, the proportion of low-angle grain boundaries $\left(2-10^{\circ}\right)$ in sample $\mathrm{E}$ was $95.1 \%$, which is significantly higher than for samples $\mathrm{C}(88.6 \%)$ and $\mathrm{D}(92.0 \%)$. Figure 5 shows the misorientation distributions of $\mathrm{Cu}_{60} \mathrm{Ni}_{40}$ alloy tapes after different annealing steps. The lowest content of twins $\left(60^{\circ}\right.$ misorientation) was found in sample $\mathrm{E}$. These $\mathrm{Cu}_{60} \mathrm{Ni}_{40}$ cube textures after one-step or two-step annealing were compared in Fig. 6. It can be seen that most grains in sample $\mathrm{E}$ were concentrated around $\pm 4.1^{\circ}$ deviation from the ideal cube orientation, agreeing with the highest content of low-angle grain boundaries (see Fig. 5), which is also expected to contribute to generating high quality superconductors.

\section{Conclusion}

(1) A strong Copper-type rolling texture, which contributes to generating cube recrystallization texture, was obtained by cold rolling ( $5 \%$ deformation per pass, $99 \%$ total deformation);

(2) The two-step annealing process could improve the $\mathrm{Cu}_{60} \mathrm{Ni}_{40}$ cube recrystallization texture. Non-magnetic $\mathrm{Cu}_{60} \mathrm{Ni}_{40}$ alloy tapes in which the amount of cube texture $\left(\leq 10^{\circ}\right)$ was $99.7 \%$ and the proportion of low-angle grain boundaries $\left(2-10^{\circ}\right)$ reaches $95.1 \%$ were produced by annealing first at $550^{\circ} \mathrm{C}$ for $30 \mathrm{~min}$ and then at $1050^{\circ} \mathrm{C}$ for $30 \mathrm{~min}$, thus reaching the same level as commercial Ni-W alloy substrates. Such high quality $\mathrm{Cu}_{60} \mathrm{Ni}_{40}$ alloy tapes may be used for the following deposition of buffer and superconductor layers.

Acknowledgements: This work was financially supported by the national natural science foundation of China (51571002), Beijing Natural Science Foundation (2172008), the Doctoral Program of Higher Education of Special Research Fund (20121103110012), Beijing Municipal Natural Science Foundation B Type (KZ201310005003), China Scholarship Council and by the Program of Beijing City and Beijing University of Technology.

\section{References}

[1] S. Kang, A. Goyal, J. Li, et al. High-performance high-T-c superconducting wires[J], Science, 2006, 311(5769): $1911-1914$.

[2] D.P. Norton, A. Goyal, J.D. Budai, et al. Epitaxial YBa2Cu3O7 on biaxially textured nickle (001) : An approach to superconducting tapes with high critical current density[J], Science, 1996, 274(5288): 755-757.

[3] Y.B. Ji, C.S. Li, H.L. Zheng, et al. Recrystallization of Ni-5\%W substrates by reel-to-reel method[J], Rare Metal Materials and Engineering, 2011, 40(9): 1526-1529.

[4] R. Huhne, J. Eickemeyer, V.S. Sarma, et al. Application of textured of highly alloyed Ni-W tapes for preparing coated conductor architectures[J], Superconductor Science \& Technology, 2010, 23(3): 034015

[5] http://www.evico.cc.

[6] Y. X. Zhou, S. V. Ghalsasi, M. Hanna, et al. Fabrication of cube-textured Ni-9\%atW substrate for YBCO superconducting wires using powder metallurgy[J]. IEEE Transactions on Applied Superconductivity, 2007, 17(2): 3428-3431.

[7] A. Girard, C E Bruzek, J L Jorda, et al. Industrial Cu-Ni alloys for HTS coated conductor tape[J], Journal of Physics Conference Series, 2006, 43: 341-344.

[8] S.S. Vadlamani, J. Eickemeyer, L. Schultz, et al. Rolling and recrystallisation textures in Cu-Al, Cu-Mn and Cu-Ni alloys[J]. Journal of Materials Science, 2007, 42(17):7586-7591.

[9] J. Eickemeyer, R. Hühne,, A. Güth, C. Rodig, et al. Textured Ni-7.5 at.\% W substrate tapes for YBCO-coated conductors[J]. Superconductor Science \& Technology, 2008, 21(10): 105012.

[10] J. Eickemeyer, R. Huhne, A. Guth, et al. Textured Ni-9.0 at.\% W substrate tapes for YBCO-coated conductors[J]. Superconductor 
Science \& Technology, 2010, 23(8): 085012.

[11] Y. Zhao, H.L. Suo, Y.H. Zhu, et al. Study on the formation of cubic texture in Ni-7 at.\% W alloy substrates by powder metallurgy routes[J]. Acta Materialia, 2009, 57(3): 773-781.

[12] A. Vannozzi, G. Celentano, A. Angrisani, et al. Nickel-Copper Alloy Tapes as Textured Substrates for YBCO Coated Conductors[J]. Journal of Physics Conference Series, 2008, 97: 012188.

[13] A. Vannozzi, G. Thalmaier, A.A. Armenio, et al. Development and characterization of cube-textured Ni-Cu-Co substrates for YBCO-coated conductors[J]. Acta Materialia, 2010, 58(3): 910-918.

[14] U. Gaitzsch, J. Eickemeyer, R. Christian, et al. Paramagnetic substrates for thin film superconductors: Ni-W and Ni-W-Cr[J]. Scripta Materialia, 2010, 62(7): 512-515.

[15] A. Tuissi, R. Corti, E. Villa, et al. Biaxially textured Ni and CuNi alloy substrate tapes for HTS coated conductor[J], Inst. Phys. Conf. Ser., 2000,167:399-402.

[16] H.Q. Qiu. Study on textured NiW and Cu alloy composite substrates used for coated conductors [D], Beijing University of technology: College of Materials Science and Engineering, 2011: 43 59

[17] F. Fan, Y.M. Lu, Z.Y. Liu, et al. Biaxially texture and magnetism in $\mathrm{Cu}-\mathrm{Ni}$ alloy for substrates of superconductor coated conductors[J]. Chinese Journal of Low Temperature Physics, 2009, 2: 102-106.

[18] J. Hirsch, K. Lucke. Mechanism of deformation and development of rolling textures in polycrystalline fcc metals .1. Description of rolling texture development in homogeneous CuZn alloys[J]. Acta metallurgica, 1988, 36(11): 2863-2882.

[19] T. Petrisor, V. Boffa, G. Celentano, et al. Epitaxial oxidation of Ni-V biaxially textured tapes[J]. Physica C-Superconductivity and its applications, 2002, 377(1-2): 135-145.

[20] G. Celentano, V. Boffa, L. Ciontea, et al. High J(c) YBCO coated conductors on non-magnetic metallic substrate using YSZbased buffer layer architecture[J]. Physica C-Superconductivity and its applications, 2002, 372: 790-793.

[21] V. Subramanya Sarma, J. Eickemeyer, A. Singh, et al. Development of high strength and strongly cube textured Ni-4.5\% W/Ni15\% Cr composite substrate for coated conductor application[J], Acta Materialia, 2003, 51(16): 4919-4927.

[22] P. Gerber, J. Tarasiuk, B. Bacroix. Influence of the rolling reduction on static recrystallization in copper[J]. Materials Science Forum, 2002, 408(4): 851-856. 